\title{
IS Fluoroscopy Necessary for SACROILIAC JOINt InJeCtions?
}

\begin{abstract}
Hans C. Hansen, MD
The use of sacroiliac joint injection has been a steadily increasing for therapeutic and diagnostic purposes in the United States. Because of the conceivably easy accessibility of sacroiliac joint and reported low incidence of morbidity, the sacroiliac joint injection is felt to be a procedure that maybe performed easily in the office based setting. While this procedure may be common, the sacroiliac joint injection is not performed accurately without the aide of imaging.

Further complicating the issue of sacroiliac joint injections is the lack of specific and

reliable diagnostic testing. Clinical evaluation and imaging studies are often unreliable and practitioners often mistakenly assume that pain over the posterior superior iliac spine is pathognomonic for sacral joint pain. In addition, referral patterns are unreliable and bedside testing is often non-diagnostic.

Sixty patients undergoing sacroiliac joint injections were studied. Sacroiliac joint injections were placed blindly then examined under fluoroscopy for accurate needle placement. The needle was placed by a single experienced spinal injectionist.

Results of blind needle placement revealed that only 5 of 60 patients were felt to have needle placement approximating a therapeutic point of contact with the sacroiliac joint. Furthermore, the posterior superior iliac spine, was found to be a poor indicator of sacroiliac joint anatomic access.

The results of this study show that accurate placement of sacroiliac joint injections is successful without fluoroscopy in only $12 \%$ of the patients, even in experienced hands. Keywords: Sacroiliac joint, fluoroscopy, diagnostic testing, intraarticular injection
\end{abstract}

As steady increase in utilization of sacroiliac joint injection finds its way into clinical practice, the question presents by who and how should this joint be injected. The mere fact that the joint is easily accessible may lure a physician into the false assumption that placing a needle at the point of maximal pain will obtain proper placement, and hence maximum therapeutic benefit. Although the true extent of improper needle placement is unknown, the fact that practitioners routinely inject this joint without fluoroscopy necessitates a systematic evaluation.

Sacroiliac joint dysfunction was considered the primary cause of low back pain from 1905 to 1934 (1). Goldthwait and Osgood (2) in 1905 mentioned sacroiliac strain as a source of low back pain. However, the discovery of lumbar disc prolapse causing low back and lower extremity pain in 1934 by Mixter and Barr (3) provided a mechanical construct for lumbar pain and interest in sacroiliac joint disappeared. Since then substantial

From The Pain Relief Centers, PA, Conover, NC Address Correspondence: Hans C. Hansen, MD, Medical Director, The Pain Relief Centers, PA, Conover, North Carolina, 3451 Greystone Place SW, Conover NC 28613, e-mail: hans@hippocrates.org Funding: There was no external funding in preparation of this manuscript. controversy over the existence and clinical relevance of sacroiliac joint dysfunction continued.

Sacroiliac joint dysfunction is considered as a clinically significant pain generator in certain patients with chronic low back pain $(1,4)$. However, the evidence with regards to sacroiliac joint dysfunction was only empirical and mainly derived from anecdotal reports, case reports, and uncontrolled trials until controlled intraarticular sacroiliac joint blocks were developed (5). Based upon history and physical examination findings, the prevalence of sacroiliac joint pain has been shown to range from $22.5 \%$ to $62.8 \%$ (4, 6-9). Utilizing controlled comparative local anesthetic blocks, the prevalence of sacroiliac joint pain in chronic low back pain population has been reported to be $10 \%$ to $30 \%$ by a single block $(10,11)$ and $10 \%$ to $19 \%$ by a double block paradigm $(12,13)$. Multiple authors also have described the effectiveness of fluoroscopically intraarticular sacroiliac joint steroid injections in patients with sacroiliac joint dysfunction (14-17).

In the diagnosis of sacroiliac joint dysfunction, sacroiliac joint injections play a crucial role. The sacroiliac joint is accepted as a potential source and/or buttock pain with or without lower extremity pain. There are no definite historical, physical, or radiological features to provide definite diagnosis of sacroiliac joint pain (10-13, 18-23), even though some have advocated $(24,25)$ reasonable ability to diagnose sacroiliac joint pain by provocative maneuvers. Thus, diagnostic blocks of sacroiliac joint can be performed in order to test the hypothesis that the sacroiliac joint is the source of the patient's pain. The sacroiliac joint can be anesthetized with intraarticular injection of local anesthetic. If pain is not relieved, the joint cannot be considered the source of pain whereupon, a new hypothesis about the source of pain is required. True-positive responses are secured by performing controlled blocks, either in the form of placebo injections of normal saline or comparative local anesthetic blocks. Consequently, accuracy of sacroiliac joint blocks depends on the validity of injection. The face validity of sacroiliac joint blocks is established by injecting contrast medium into the joint in order to show that the needle has entered the joint cavity and that solutions that are injected do not escape from the cavity to reach other structures that might conceivably be an alternative source of pain $(5,26)$. The construct validity of sacroiliac joint blocks is secured by performing comparative local anesthetic blocks similar to facet joint blocks (5). Maigne et al 
(12) established that the false-positive rate of single, uncontrolled, sacroiliac joint injections was $20 \%$. False-positive injection may occur with extravasation of anesthetic agent out of the joint secondary to defects in the joint capsule. Similarly, falsenegative results may occur from faulty needle placement, intravascular injection or inability of the local anesthetic agent to reach the painful portion of the joint due to loculations.

Thus, for a sacroiliac joint injection to be valid, it has to be performed under fluoroscopic visualization. Since many physicians perform sacroiliac joint injections, it is conceived that these injections do not provide any valuable information. Rosenberg et al (27) documented that successful sacroiliac joint injections without fluoroscopy were only $22 \%$. Further, they also reported that epidural spread was seen in $24 \%$ of the patients with foraminal filing noted in $44 \%$ of the patients.

This study was undertaken to evaluate successful needle placement into the sacroiliac joint without fluoroscopy.

\section{Methods}

Of the sixty patients referred to the Pain Relief Centers for SI joint injection, every attempt was made to clearly define the SI joint as a pain generator. All appropriate provocative tests were utilized along with review of imaging studies. The SI joint was considered as the pain-producing entity if clear discogenic pathology had been ruled out, there was only modest to no evidence of facet joint pathology, and Gaenslen's and
Patrick's signs were positive. The patient also demonstrated a pain level consistent with impairment secondary to his/ her pain, and no evidence of neurological progression existed.

After informed consent was obtained, the patient was then taken to the fluoroscopy suite and placed in prone position. An experienced spinal injectionist marked and identified traditional landmarks felt to be indicative of SI joint identity. Point of maximum tenderness was identified in each patient. Using best estimation and approach, a needle was placed blindly, under local anesthetic, and then imaged by fluoroscopy to assess needle placement. If the needle was felt to approximate the SI joint, $2 \mathrm{~mL}$ of Isovue was injected. Accuracy of placement of needle and contrast distribution was assessed by fluoroscopy.

\section{RESULTS}

Of the sixty patients chosen for blind injection, only five patients were felt to have received proper joint access that would be necessary for therapeutic SI joint injection. Fifteen patients were injected at the patient's description of "most intense pain", which was within $5 \mathrm{~cm}$ of the posterior superior iliac spine. None of these injections, inclusive of the five patients felt to have received close approximation to the joint, provided proper intraarticular placement or arthrography. The remainder of the patients had varied needle placement. Figs 1 and 2 demonstrate placement of needles with and without fluoroscopy.

\section{Discussion}

In the experienced hand of a spinal injectionist, the sacral joint was not properly accessed in sixty patients. It is determined that the needle must be guided by fluoroscopy, and that the joint is not an easily accessible joint as many would believe. The blind injection could best be described as a major joint, ligament or trigger point injection. If joint laxity is a problem with the SI joint as many believe, frequent injections at posterior superior iliac spine would only be placing steroid in ligamentous tissue that will rarely afford any close approximation to a true SI joint injection, and possible further aggravating a lose joint.

In modern medicine, sacroiliac joint is an accepted source of low back and/or buttock pain with or without lower extremity pain. The sacroiliac joint receives its innervation from the lumbosacral nerve roots (28-33). Further, referral patterns of sacroiliac joint provocation or irritation have been published (34, $35)$. To continue to believe that sacroiliac joint is an accepted source of low back and/or lower extremity pain, it is essential to maintain the accuracy of diagnostic blocks. This can only be achieved by fluoroscopic imaging.

\section{Conclusion}

This study shows that, blind placement of needle, potentially into the sacroiliac joint reaches the joint only in approximately $12 \%$ of the patients. Thus, we conclude that sacroiliac joint injections must be performed under fluoroscopic visualization only.

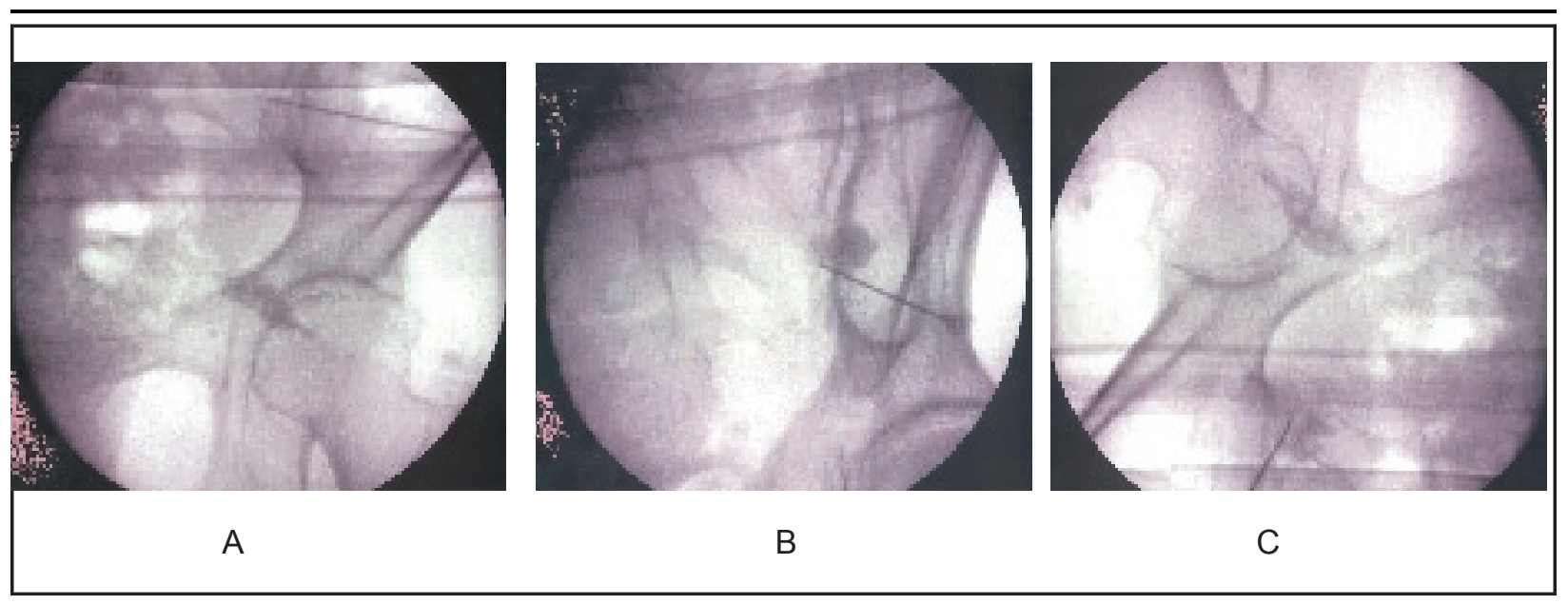

Fig. 1. Illustration of Inaccurate Placement of Needle Placed Blindly and Evaluated under Fluoroscopy 


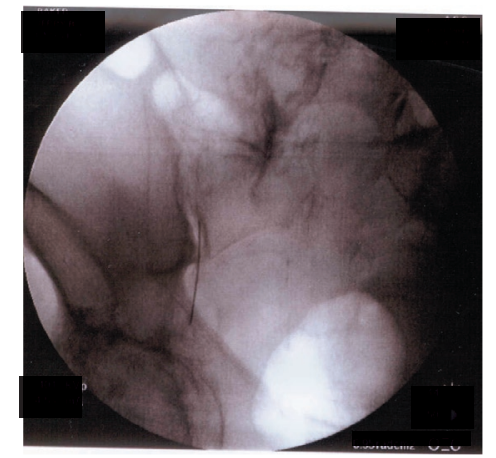

A

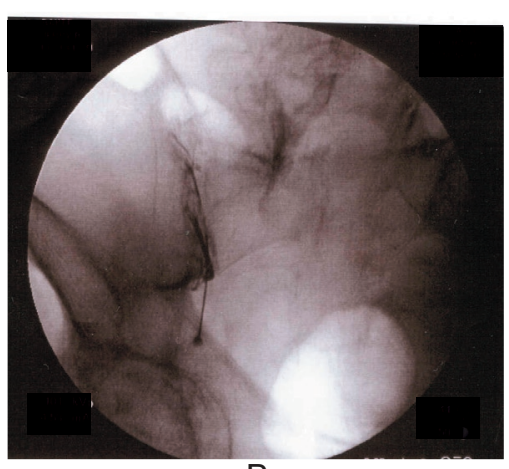

B

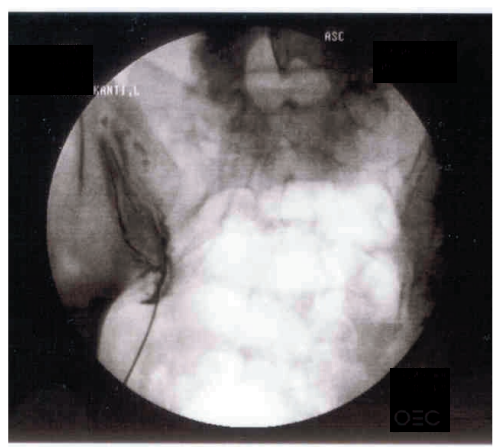

C

Fig. 2. Illustration of Accurate Placement of Needle under Fluoroscopy with Intraarticular Contrast Injection

\section{Author Affiliation \\ Hans C Hansen, MD}

Medical Director

The Pain Relief Centers, PA

3451 Greystone Place SW

Conover NC 28613

e-mail: hans@hippocrates.org

\section{REFERENCES}

1. Slipman CW, Whyte WS, Chow DW et al. Sacroiliac joint syndrome. Pain Physician 2001; 4:143-152.

2. Goldthwait GE, Osgood RB. A consideration of the pelvic articulations from an anatomical, pathological, and clinical standpoint. Boston Med Surg / 1905; 152 : 593-601.

3. Mixter WJ, Barr JS. Rupture of the intervertebral disc with involvement of the spinal canal. N Eng J Med 1934; 211:210-215.

4. Hodge JC, Bessette B. The incidence of sacroiliac joint disease in patients with low back pain. Can Assoc Radiol J 1999; 50:321-323.

5. Manchikanti L, Staats P, Singh V et al. Evidence-based practice guidelines for interventional techniques in the management of chronic spinal pain. Pain Physician 2003; 6:3-87.

6. Bernard TN, Cassidy JD. The sacroiliac joint syndrome. Pathophysiology, diagnosis and management. In Frymoyer JW (ed). The Adult Spine: Principles and Practice, 2nd Ed. Lippincott-Raven Publishers, Philadelphia, 1997; pp 2343-2363.

7. Bernard T, Kirkaldy-Willis W. Recognizing specific characteristics on non-specific lower back pain. Clin Orthop 1987; 217: 266-280.

8. Greenman PE. Sacroiliac dysfunction in the failed low back syndrome. Proceedings of the First Interdisciplinary World Congress on Low Back Pain and its Rela- tion to the Sacroiliac Joint, San Diego, November 5-6, 1992; pp 329-352.

9. Dejung B. Iliosacrolgelenkblockierungen. Eine Verlaufstudie. Nanuele Medizin 1985; 23:109-115.

10. Pang WW, Mok MS, Lin ML et al. Application of spinal pain mapping in the diagnosis of low back pain - analysis of 104 cases. Acta Anaesthesiol Sin 1998; 36:71-74.

11. Schwarzer AC, Aprill CN, Bogduk N. The sacroiliac joint in chronic low back pain. Spine 1995; 20:31-37.

12. Maigne JY, Aivakiklis A, Pfefer F: Results of sacroiliac joint double block and value of sacroiliac pain provocation test in $54 \mathrm{pa}$ tients with low back pain. Spine 1996; 21: 1889-1892.

13. Manchikanti L, Singh V, Pampati V et al. Evaluation of the relative contributions of varinus strurtures in chrnnir lnw hark pain. Pain Physician 2001; 4:308-316.

14. Slipman CW, Plastaras CT, Yang ST et al. Outcomes of therapeutic fluoroscopic guided sacroiliac injections for definitive sacroiliac joint syndrome. Arch Phys Med Rehab 1996; 77:937.

15. Norman GF, May A. Sacroiliac conditions simulating intervertebral disc syndrome. West J Surg 1956; 64:461-462.

16. Maugers Y, Mathis C, Berthelot JM et al. Assessment of the efficacy of sacroiliac corticosteroid injections in spondyloarthropathies: a double blind study. Br Jour Rheum 1996; 35: 767-770.

17. Pulisetti D, Ebraheim NA. CT-Guided sacroiliac joint injections. / Spinal Disord 1999; 12:310-312.

18. Slipman CW, Jackson HB, Lipetz JL et al. Sacroiliac joint pain referral zones. Arch Phys Med Rehabil 2000; 81:334-337.

19. Dreyfuss $P$, Michaelson M, Pauza $K$ et al. The value of medical history and physical examination in diagnosing sacroiliac joint pain. Spine 1996; 21:2594-2602.

20. Dreyfuss P, Dreyer S, Griffin J et al. Positive sacroiliac screening tests in asymptomatic adults. Spine 1994; 19:1138-1143.
21. Slipman CW, Huston CW. Sacroiliac joint syndrome. In Manchikanti L, Slipman CW, Fellows B (eds), Interventional Pain Management: Low Back Pain - Diagnosis and Treatment. ASIPP Publishing, Paducah, KY 2002; pp 565-572.

22. Vogler JB III, Brown WH, Helms CA et al. The normal sacroiliac joint: A CT study of asymptomatic patients. Radiology 1984; 151:433-437.

23. Tullberg T, Blomberg S, Branth B et al. Manipulation does not alter the position of the sacroiliac joint: A roentgen stereophotogrammatic analysis. Spine 1998; 23:1124-1129.

24. Slipman CW, Sterenfeld EB, Chou LH, et al. The predictive value of provocative sacroiliac joint stress maneuvers in the diagnosis of sacroiliac joint syndrome. Arch Phys Med Rehab 1998; 79:288-292.

25. Broadhurst NA, Bond MJ. Pain provocation tests for the assessment of sacroiliac joint dysfunction. / Spin Disord 1998; 11: 341-345.

26. Slipman CW, Huston CW. Diagnostic sacroiliac joint injections. In Manchikanti L, Slipman CW, Fellows B (eds), Interventional Pain Management: Low Back Pain - Diagnosis and Treatment. ASIPP Publishing, Paducah, KY 2002; pp 269-274.

27. Rosenberg JM, Quint TJ, de Rosayro AM. Computerized tomographic localization of clinically-guided sacroiliac joint injections. Clin J Pain 2000; 16:18-21.

28. Fortin JD, Kissling RO, O'Connor BL et al. Sacroiliac joint innervation and pain. Am J Orthop 1999; 28:687-690.

29. Grob KR, Neuhuber WL, Kissling RO. Innervation of the sacroiliac joint of the human. Z Rheumatol 1995; 54:117-122.

30. Ikeda R. Innervation of the sacroiliac joint. Macroscopical and histological studies. Nippon Ika Daigaku Zasshi 1991; 58:587-596.

31. Vilensky JA, O'Connor BL, Fortin JD et al. Histologic analysis of neural elements in the human sacroiliac joint. Spine 2002; 27:1202-1207. 
32. Sakamoto N, Yamashita T, Takebayas hi T et al. An electrophysiologic study of mechanoreceptors in the sacroiliac joint and adjacent tissues. Spine 2001; 26: E468-E471.

33. Murata $\mathrm{Y}$, Takahashi $\mathrm{K}$, Yamagata $\mathrm{M}$ et al. Origin and pathway of sensory nerve fibers to the ventral and dorsal sides of the sacroiliac joint in rats. J Orthop Res 2001; 19:379-383.

34. Fortin JD, Dwyer AP, West S et al. Sacroiliac joint: Pain referral maps upon applying a new injection/arthrography technique. Part I: Asymptomatic volunteers. Spine 1994; 19:1475-1482.
35. Fortin JD, Aprill CN, Ponthieux B et al. Sac roiliac joints: Pain referral maps upon applying a new injection/arthrography technique. Part II: Clinical evaluation. Spine 1994; 19:1483-1489. 